\title{
Simulation of Matrix Converter by using MATLAB-Simulink
}

\author{
Mr. Abhinav V. Deshpande \\ Internal Full Time (IFT) Ph. D. Research Scholar \\ School of Electronics Engineering (SENSE) \\ Vellore Institute of Technology (VIT), Vellore, Tamil Nadu, India-632014 \\ avd.a.deshpande@gmail.com
}

\begin{abstract}
:
The matrix converter converts the input line voltage into a variable voltage with an unrestricted output frequency without using an intermediate circuit, dc link circuit. A pure sine in and pure sine out is the unique feature of the matrix converter. This research paper also analyzes the basic operating principle and the simulation modeling of the direct matrix converter, which is controlled by the Space Vector Pulse Width Modulation technique by using the software which is known as MATLAB/Simulink. The most desirable features in the power frequency changes can be fulfilled by using the matrix converters, and this is the reason for the tremendous interest in the topology. Since the power electronic circuits which is known as the motor drives are used to operate the AC motors at the frequencies other than that of the supply.
\end{abstract}

Keywords: Direct Matrix Converter (DMC), Space Vector Modulation (SVPWM), AC-AC Power Conversion, Converters, Simulation

\section{Introduction:}

A three phase matrix converters are capable of providing a simultaneous amplitude and the frequency transformation of a three-phase voltage system and do need only a small switching frequency AC filter component as opposed to the conventional two stage AC/DC/AC conversion by using the back-to-back connection of the current or the voltage DC link PWM converter systems. Furthermore, the matrix converters are inherently bidirectional and therefore can regenerate the energy back into the mains from the load side where the mains current is sinusoidal and the displacement factor seen by the mains can be adjusted by using a proper modulation irrespective of the type of load. The most desirable features in the power frequency changers are given as below:

[1] Simple and compact power circuit

[2] Generation of load voltage with an arbitrary amplitude and frequency

[3] Sinusoidal input and output currents

[4] Operation with unity power factor for any type of load

[5] Regeneration capability.

The ideal characteristics can be fulfilled by using the matrix converters, and this is the reason for the tremendous interest in the topology [1]. Furthermore, the matrix converters are inherently bidirectional and therefore can regenerate the energy back into the mains from the load side where the mains current is sinusoidal and the displacement factor seen by the mains can be adjusted by using a proper modulation irrespective of the type of the load. In consequence matrix converters show a highpower density and due to the lacking of the electrolytic capacitors a high reliability potentially. Accordingly, there is considerable interest in the application of the matrix converters for the realization of a highly compact three phase AC drives for industrial, military and the avionic system.

\section{Main Objectives of Study:}

Power electronic devices which are known as the motor drives are used to operate the $\mathrm{AC}$ motors at the frequencies other than that of the supply. These consist of two main sections, a controller to set the operating frequency and a three-phase converter in order to generate the required sinusoidal three phase system voltage. The Direct Matrix Converter (DMC) consist of nine bidirectional switches which are required to be commutated in the right way and sequence in order to minimize the 
losses and produce the desired output with a high-quality input and the output waveforms. This research paper also analyzes the basic operating principle and the simulation modeling of the direct matrix converter, which is controlled by a Space Vector Pulse Width Modulation technique by using the software which is known as MATLAB/Simulink.

\section{Direct Matrix Converters:}

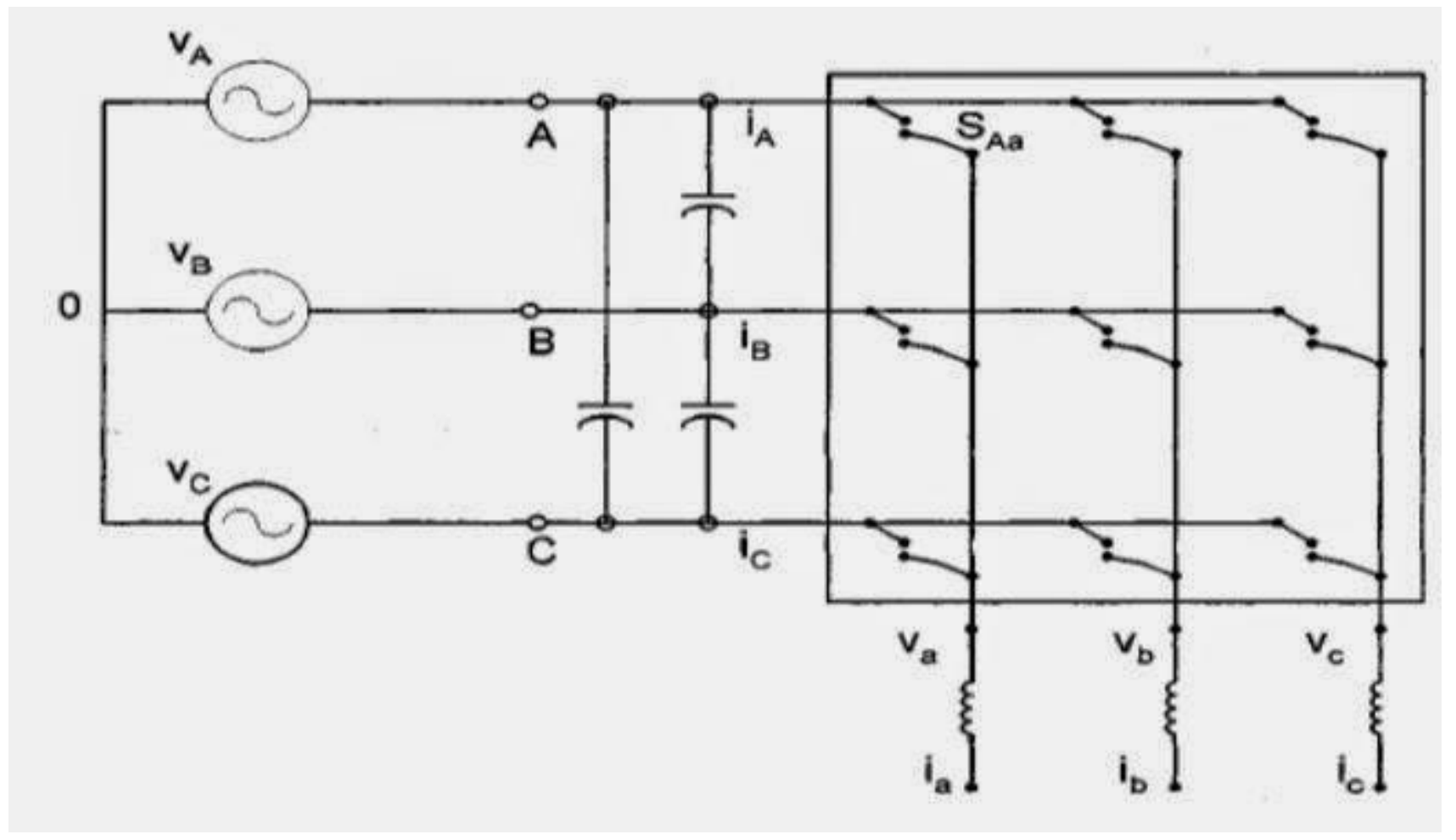

Figure 1 Direct Matrix Converter Schematic Block Diagram

A matrix converter is a device which is used for converting AC energy into the AC energy directly. The main feature of this device is to convert the magnitude as well as the frequency of the input into a desired magnitude and the frequency of the output by using power semiconductor devices. Hence, a matrix converter is also known as the PWM frequency changers. The circuit is called as a matrix converter as it provides nine switches which are arranged in a $3 \times 3$ matrix fashion [2]. The matrix converter is a development of the force commutated cycloconverter which is based on a bidirectional fully controlled switches, incorporating the PWM voltage control. The schematic circuit diagram of the most practical three phase to the three-phase matrix converter is shown in Figure 1. A conventional matrix converter does employ 9 bidirectional bipolar (four quadrant) switches which is based on a available power semiconductor technology have to be formed by 18 unipolar turn off power semiconductors (IGBT's) and 18 diodes. The combination of 2 IGBT's and 2 anti-parallel diodes per four quadrant switches does allow a selective turn on of the switch for each current direction as required for the implementation of a safe multistep commutation strategy by avoiding the short circuiting of an input line-to-voltage or an abrupt interruption of an output phase current. The converter consists of 9 bidirectional switches which are arranged in the sets of 3 , so that any of the three input phases can be connected to any of the three output lines, where the lowercase and uppercase letters are used to denote the input and the output respectively. The switches are then controlled in such a way that the average output voltages are a three-phase set of the sinusoids of the required frequency and magnitude. The key element in a matrix converter is the fully controlled four quadrant bidirectional switch, which allows a high frequency operation. In order to achieve a higher power density and reliability, it makes sense to consider the matrix converters which achieve a three phase AC/AC conversion without any intermediate energy storage element. Generally, by employing the matrix converters, the storage element in the DC link is eliminated at the cost of a larger number of semiconductors. However, a mains filter is necessary in order to smooth the pulsed currents on the input side of the matrix converter. By using a sufficiently high pulse frequency, the output voltage and the input current both are shaped sinusoidally. With the initial progress, it has received a considerable attention as it provides a good alternative to the double sided PWM voltage source rectifier-inverters. The matrix converter should be controlled by using a specific and appropriately timed sequence of the values of the switching variables, which will result in the balanced output voltages by having the desired frequency and amplitude, while the input currents are balanced and in phase (for unity input displacement factor (IDF) or at an arbitrary angle (for a controllable IDF) with respect to the input voltages. As the matrix converter in theory can operate at any frequency at the output or the input by including a zero it 
can be employed as a three phase AC/DC converter, DC/three phase AC converter, or even a buck/boost DC chopper and thus as a Universal Power Converter [7].

\section{Operation and Control Methods of Matrix Converters:}

The matrix converter should be controlled by using a specific and appropriately timed sequence of the values of the switching variables. The switching function for a MC is defined as follows:

$\mathrm{S}_{\mathrm{Kj}}=\mathrm{I}$, the switch is closed which means that $\mathrm{t}=0$, which means that the switch is open, where $\mathrm{K}, \mathrm{j}=\{1,2,3\}$ Eqn. (1)

The constraints are expressed as follows:

$\mathrm{S}_{\mathrm{K} 1}+\mathrm{S}_{\mathrm{K} 2}+\mathrm{S}_{\mathrm{K} 3}=1, \mathrm{~K}=\{1,2,3\}$

The converter in Figure 1 connects any input phase $(\mathrm{a}, \mathrm{b}, \mathrm{c})$ to any output phase $(\mathrm{A}, \mathrm{B}, \mathrm{C})$ at any instant. When connected, the voltages $V_{A}, V_{B}, V_{C}$ at the output terminals are related to the input voltages $V_{a}, V_{b}, V_{c}$ as in Eqn. (2) where $S_{11}$ through $S_{33}$ are the switching variables of the corresponding switches. For a balanced linear star-connected load at the output terminals, the input phase currents $I_{a}, I_{b}, I_{c}$ are related to the output phase currents $I_{A}, I_{B}, I_{C}$ as given in Eqn. (3). Note that the matrix of the switching variables as given in Eqn. (2) is a transpose of the respective matrix as given in Eqn. (3).

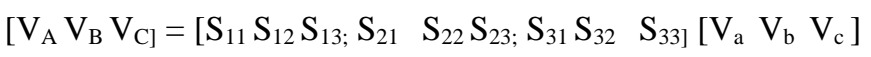



Eqn. (3)

\section{Pulse Width Modulation:}

The control of the electric power is performed by using power converters. The converters transfer the energy from a source in a switched operation mode that ensures a high efficiency of the conversion. The algorithm that generates the switching functions is called as the Pulse Width Modulation techniques. The function of the converter is to change the input voltage magnitude to a symmetrical output voltage of the desired magnitude and frequency. The PWM techniques are necessary in order to perform the following tasks:

[1] Control converter output frequency

[2] Control converter output voltage

[3] Minimize the harmonic distortion

The proliferation of the power electronic devices has led to a demand for more effective Pulse Width Modulation strategies. One of the PWM techniques which is named as the Space Vector Pulse Width Modulation (SVPWM) is chosen for the process of simulation. The process of modulation is the procedure which is used to generate the appropriate firing pulses to each of the nine bidirectional switches [4].

\subsection{Space Vector Pulse Width Modulation (SVPWM):}

The SVPWM method is now a well documented PWM control technique that yields a high voltage gain and less harmonic distortion as compared to the other modulation techniques. Here, the three phase input currents and the output voltages are represented as the space vectors. The SVPWM algorithm which is used to control the matrix converters have shown an inherent capability in order to achieve a full control of the instantaneous output voltage vector and the instantaneous current displacement angle even under the supply voltage disturbances [6]. By representing three phase quantities as the Space Vectors is particularly useful for the power electronic applications. Essentially this method defines a three-phase system with a single unity vector.

$\mathrm{U}_{\mathrm{s}}=\left(1+\mathrm{a}+\mathrm{a}^{2}\right)$ where $\mathrm{a}=\mathrm{e}^{\mathrm{j} 2 \pi / 3}$

By using this unity vector, a space vector representation of the phase voltages $v_{a}, v_{b}, v_{c}$ is therefore

$\mathrm{V}=2 / 3\left(\mathrm{v}_{\mathrm{a}}+\mathrm{a} \mathrm{v}_{\mathrm{b}}+\mathrm{a}^{2} \mathrm{vc}\right)$

Eqn. (5) 
The algorithm is based on the concept that the MC output line voltages for each switching combination can be represented as a voltage space vector which is defined by using the relationship which is given as below:

$\mathrm{V}_{0}=2 / 3\left(\mathrm{v}_{\mathrm{a}}+\mathrm{v}_{\mathrm{bc}} \mathrm{e}^{(\mathrm{j} 120)}+\mathrm{v}_{\mathrm{ca}} \mathrm{e}^{(-\mathrm{j} 120)}\right)$

The $(2 / 3)$ scaling factor is necessary in order to ensure that the system remains power invariant. For each combination, the input and the output line voltages can be expressed in terms of the space vectors as:

$\mathrm{V}_{\mathrm{i}}=\mathrm{V}_{\mathrm{i}} \mathrm{e}^{\mathrm{\alpha i}} ; \mathrm{V}_{\mathrm{o}}=\mathrm{V}_{\mathrm{o}} \mathrm{e}^{\alpha \mathrm{O}}$

The input and the output line currents can be expressed as follows:

$I_{i}=I_{i} e^{\beta i} ; I_{O}=I_{O} e^{\beta O}$

The modulation method involves the selection of the vectors and there on time computation. At each sampling period $\mathrm{T}_{\mathrm{s}}$, the algorithm selects four active vectors which are related to any possible combinations of the output voltage and the input currents in addition to the zero vectors to construct a desired reference voltage. The amplitude and the phase angle of the reference voltage vector are calculated and the desired phase angle of the input current vector is determined well in advance. For the process of computation of the on-time periods of the chosen vectors, these are combined into two sets leading to two new vectors which are adjacent to the reference voltage vector in the sector and having the same direction as the reference voltage vector. The integral value of the reference vector is calculated over one sample time interval as the sum of the products of the two adjacent vectors and their on-time ratios. The process is repeated at every sample instant. By knowing the phase voltage for a given switching state is important for the technique which is known as Space Vector Pulse Width Modulation. The problems such as the harmonic distortion in the phase currents are responsible for the copper losses in the induction motor. Although the current waveform can be improved by increasing the frequency of the carrier wave this approach reduces the copper losses at the expense of increased switching losses. In order to overcome the limitations of the existing switching strategies, a new technique which is known as the Space Vector Pulse Width Modulation (SVPWM) is now becoming widely used in the industry.

\subsubsection{Selection of the Switching Vectors:}

The switches should be controlled in such a way that at any time, one and only one of the three switches which are connected to an output phase must be closed in order to prevent the "short circuiting" of the supply lines or the interrupting the load current flow in an inductive load. With these constraints, it can be visualized that from the possible 512 , that is $\left(2^{\circ}\right)$ states of the converter, in which only 27 , that is, $\left(3^{3}\right)$ switch combinations are allowed as given in Table 1 , which includes the resulting output line voltages and the input phase currents. These combinations are divided into three groups. Group I consist of six combinations when each output phase is connected to a different input phase. In Group II, there are 18 combinations with two output phases which are short circuited (which are connected to the same input phase). Group III includes three combinations with all the output phases which are short circuited. An AC input LC filters can be used to eliminate the switching ripples which are generated in the converter and the load is assumed to be sufficiently inductive in order to maintain the continuity of the output currents [3]. In the table, "P" represents the forward path of the current flow, that is, from the supply to the load and "N" represents the reverse path of the current flow that is fro load to the supply. Of the three groups in Table I which is given below, only the switching combinations of Group II and Group III are employed for the SVPWM method. Group II consists of the switching state voltage vectors which are having constant angular positions and are called as active or the stationary vectors. Each sub group of Group II determines the position of the resulting output voltage space vector and the six state space voltage vectors form a six sectored hexagon which is used to synthesize the desired output voltage vector. Group III comprises the zero vectors which are positioned at the center of the output voltage hexagon and these are suitably combined with the active vectors for the output voltage synthesis. By projecting this stationary voltage and the current vectors to the $\alpha-\beta$ plane, the voltage and the current hexagons which are as shown in Figure 2 and Figure 4 are obtained.

The SVPWM is based on two aspects which are given as below:

Firstly, at any particular instant, the reference output voltage vector can be in any of the six vectors of Figure 2 . From the corresponding three phase voltage waveforms in Figure 3 of that sector one of the line-line voltages is bound to be the most positive or the most negative which is denoted as the peak line. Amongst the 18 active vectors, we will choose the suitable ones which gives the non-zero voltage values for the peak line. For example, when the current reference vector is in the sector 1 which is shown in Figure 2 and Figure 3), then the peak line voltage is $\mathrm{V}_{\mathrm{OAB}}$ and the vectors which are having the non-zero 
values for $\mathrm{V}_{\mathrm{AB}}$ from the table 1 is $1 \mathrm{P}$ to $6 \mathrm{~N}$ and which is 12 in total. Now the selection is amongst these 12 active vectors and it is based on the second aspect. It is aimed at keeping the input power factor unity and achieving the maximum voltage transfer ratio. For achieving a unity power factor, the input phase current must be always maintained in phase with the phase voltage which lags behind the corresponding line-line voltages by 30 . Similarly, for achieving the maximum voltage transfer, the peak line has to be switched to the maximum input line-line voltage at that instant. At any particular instant, the reference input current vector can be in any of the six vectors of Figure 4. When the reference current vector is in the lower 30 range of a particular sector, the corresponding input voltage vector will be in the same sector as that of the current reference. But when the reference current vector moves to the next sector and the line-line which is giving the maximum input voltage value is also switched from one another which is given in Figure 4 and Figure 5. For example, when the current reference vector is in the sector 1, the input voltage vector can be I either sector 1 or sector 2. In Figure 5, the maximum input line-line voltage in the sector 1 is $\mathrm{V}_{\mathrm{ab}}$ and that in the sector 2 is $-\mathrm{V}_{\mathrm{ca}}$. If the output voltage is in sector 1 , then the vectors with $\mathrm{V}_{\mathrm{AB}}=\mathrm{V}_{\mathrm{ab}}$ or $-\mathrm{V}_{\mathrm{ca}}$ has to be chosen amongst the 12 vectors which are selected based on the first aspect. Then the active vector to be switched becomes $1 \mathrm{P}, 4 \mathrm{~N}, 6 \mathrm{P}$ and $3 \mathrm{~N}$. That means 4 in total. Thus, in one sampling period five vectors need to be switched including the zero vectors.

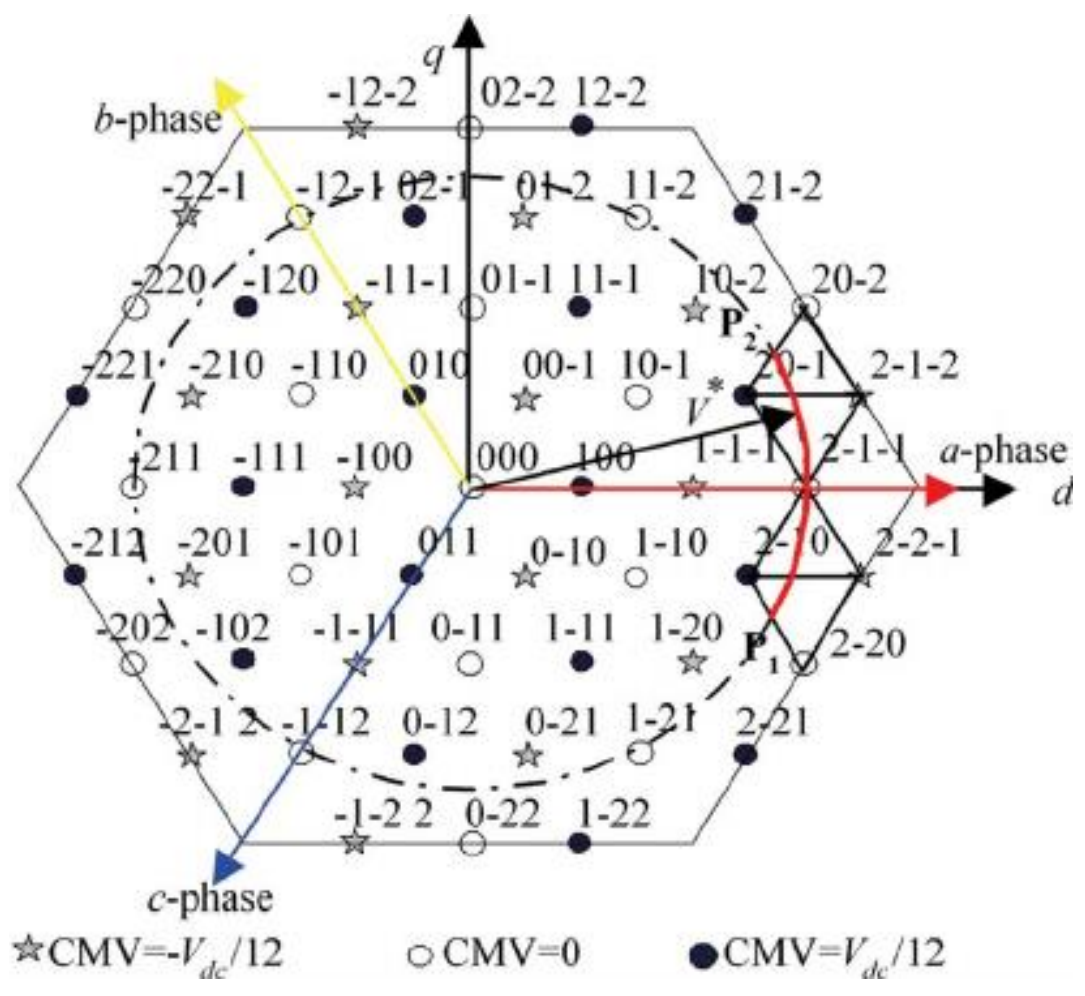

Figure 2 Output Voltage Vectors 


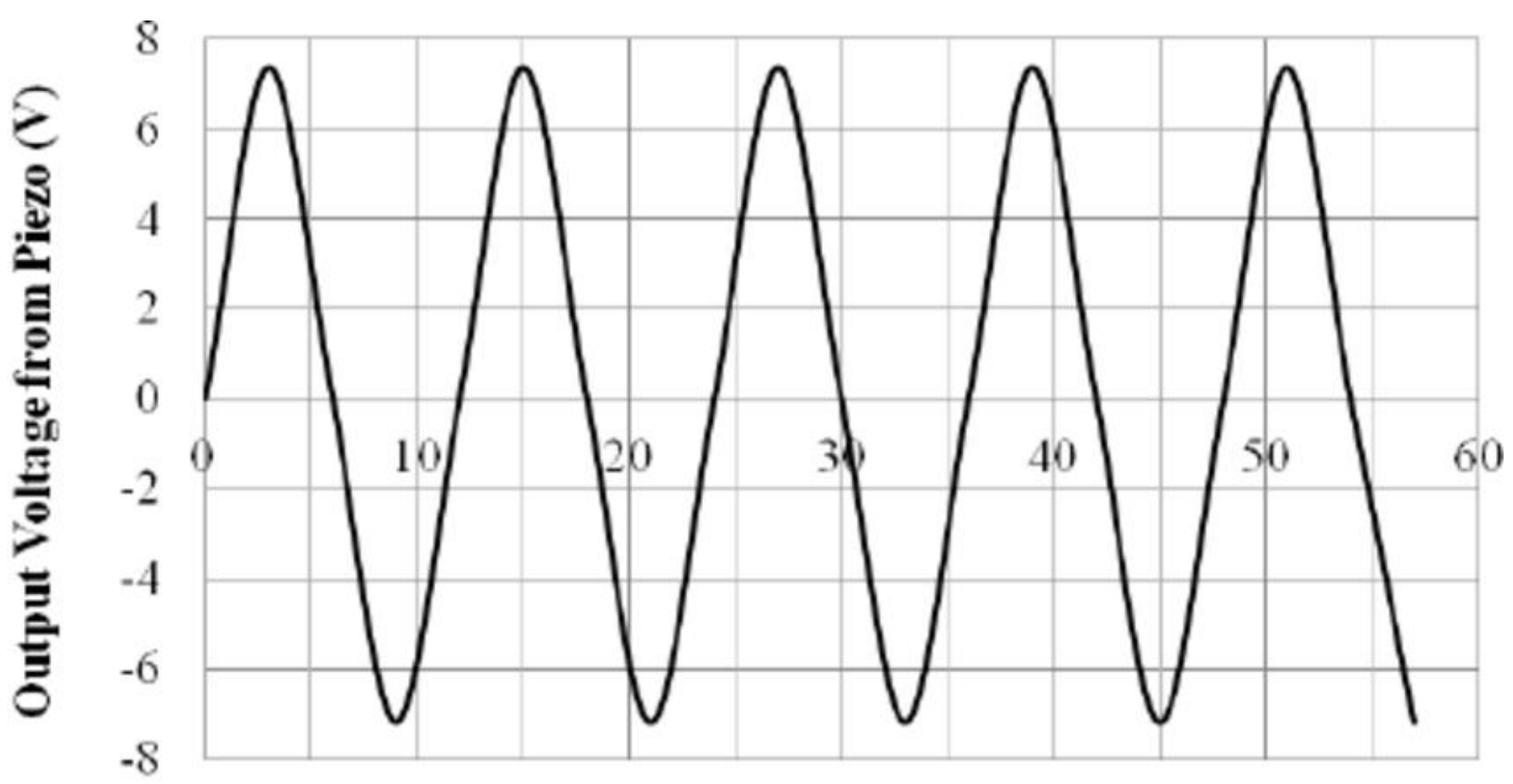

Time (ms)

Figure 3 Output Voltage

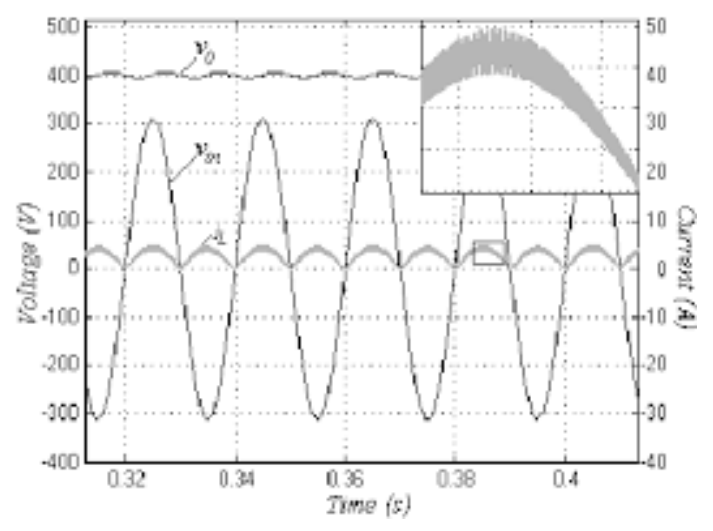

Figure 4 Input Voltage

\subsubsection{Computation of the Vector Time Intervals:}

In SVPWM, the reference output voltage vector in each sampling period is expressed as a weighted average combination of the four active state vectors and one null state vector. If $\mathrm{V}_{1}, \mathrm{~V}_{2}, \mathrm{~V}_{3}$ and $\mathrm{V}_{4}$ are the active voltage vectors and $\mathrm{V}_{0}$, the zerovoltage vector then

$V_{\text {ref Ts }}=V_{1} T_{1}+V_{2} T_{2}+V_{3} T_{3}+V_{4} T_{4}+V_{0} T_{0}$

where $T_{1}, T_{2}, T_{3}, T_{4}$ and $T_{0}$ are the time durations of the application of $V_{1}, V_{2}, V_{3}, V_{4}$ and $V_{0}$ respectively. Similarly, if $I_{1}, I_{2}, I_{3}$ and $\mathrm{I}_{4}$ are the active current vectors and $\mathrm{I}_{0}$ are the zero current vectors, then

$I_{r e f} T_{s}=I_{1} T_{1}+I_{2} T_{2}+I_{3} T_{3}+I_{4} T_{4}+I_{0} T_{0}$

Eqn. (10)

$\mathrm{T}_{0}=\mathrm{T}_{\mathrm{s}}-\left(\mathrm{T}_{1}+\mathrm{T}_{2}+\mathrm{T}_{3}+\mathrm{T}_{4}\right)$

Eqn. (11)

where $T_{1}, T_{2}, T_{3}, T_{4}$ and $T_{0}$ are the time durations of the application of $I_{1}, I_{2}, I_{3}, I_{4}$ and $I_{0}$ respectively. By resolving the Equations (9) and (10) along the mutually perpendicular $\alpha-\beta$ axis, we will get the four equations with four unknowns. The solution of these equations yields $\mathrm{T}_{1}, \mathrm{~T}_{2}, \mathrm{~T}_{3}$ and $\mathrm{T}_{4}$. The substitution of Eqn. (11) yields $\mathrm{T}_{0}$. 


\subsubsection{Selection of the Switching Sequence:}

In each sampling duration, there are five vectors to be switched including the zero vectors. The selection of the sequence should be such that the transition from one switch combination to another in the sequence should cause a minimum switch position change. This reduces the switching losses in the converter. The switching sequence so selected for different combinations is given in Table 2. For SVPWM, the sequence which is provided is for half of the sampling period. For the other half it will be repeated in the descending order.

\subsubsection{Generation of the Switching Control Signals:}

In order to generate the switching control sequence, a high frequency triangular carrier with a frequency which is the same as that of the sampling frequency $\left(\mathrm{f}_{\mathrm{s}}\right)$ is generated. The peak of the carrier is set the same as that $\mathrm{f}_{0}$ the sampling time period $\left(\mathrm{T}_{\mathrm{s}}\right)$. Four timers are loaded with time durations $T_{1}, T_{1}+T_{2}, T_{1}+T_{2}+T_{3}$ and $T_{1}+T_{2}+T_{3}+T_{4}$. The comparison of the timer values with the triangular wave generates a Duration ID which along with the Sector ID is combined as an index for the selection of the control signals from a look up table which need to store only the switch position status for 21 vectors which is illustrated in Table 3.

Table 1 Generation of Vector Duration ID and Vector to be Switched

\begin{tabular}{|c|c|c|}
\hline Condition & Duration ID & Vector to be Switched \\
\hline $0<\mathrm{V}_{\mathrm{tri}}<\mathrm{T}_{1}$ & 1 & $\mathrm{~V}_{1}$ (Active Vector) \\
\hline $\mathrm{T}_{1}<\mathrm{V}_{\mathrm{tri}}<\mathrm{T}_{1}+\mathrm{T}_{2}$ & 2 & $\mathrm{~V}_{2}$ (Active Vector) \\
\hline $\mathrm{T}_{1}+\mathrm{T}_{2}<\mathrm{V}_{\mathrm{tri}}<\mathrm{T}_{1}+\mathrm{T}_{2}+\mathrm{T}_{3}$ & 3 & $\mathrm{~V}_{3}$ (Active Vector) \\
\hline $\begin{array}{c}\mathrm{T}_{1}+\mathrm{T}_{2}+\mathrm{T}_{3}<\mathrm{V}_{\mathrm{tri}}<\mathrm{T}_{1}+\mathrm{T}_{2}+\mathrm{T}_{3} \\
+\mathrm{T}_{4}\end{array}$ & 4 & $\mathrm{~V}_{4}$ (Active Vector) \\
\hline $\mathrm{T}_{1}+\mathrm{T}_{2}+\mathrm{T}_{3}+\mathrm{T}_{4}<\mathrm{V}_{\mathrm{tri}}<\mathrm{T}_{\mathrm{s}}$ & 5 & $\mathrm{~V}_{0}$ (Zero Vector) \\
\hline
\end{tabular}

\subsubsection{Generation of the Output Voltage and Input Current:}

Once the switching pattern is generated, the output voltage and the input current can be generated by implementing Eqn. (2) and Eqn. (3).

Table 2 Logic for Generation of Index and Selection of Vector to be Switched

\begin{tabular}{|c|c|c|}
\hline Index & Sector ID.Duration ID & Vector to be switched \\
\hline 1 & $1.1,6.3,7.1,12.3$ & $1 \mathrm{P}$ \\
\hline 2 & $3.4,4.2,9.4,10.2$ & $1 \mathrm{~N}$ \\
\hline 3 & $2.3,3.1,8.3,9.1$ & $2 \mathrm{P}$ \\
\hline 4 & $5.4,6.2,11.4,12.2$ & $2 \mathrm{~N}$ \\
\hline 5 & $4.3,5.1,10.3,11.1$ & $3 \mathrm{P}$ \\
\hline 6 & $1.4,2.2,7.4,8.2$ & $3 \mathrm{~N}$ \\
\hline 7 & $3.3,4.1,13.1,18.3$ & $4 \mathrm{P}$ \\
\hline 8 & $1.2,6.4,15.4,16.2$ & $4 \mathrm{~N}$ \\
\hline 9 & $5.3,6.1,14.3,15.1$ & $5 \mathrm{P}$ \\
\hline 10 & $2.4,3.2,17.4,18.2$ & $5 \mathrm{~N}$ \\
\hline 11 & $1.3,2.1,16.3,17.1$ & $6 \mathrm{P}$ \\
\hline 12 & $4.4,5.2,13.4,14.2$ & $6 \mathrm{~N}$ \\
\hline 13 & $9.3,10.1,15.3,16.1$ & $7 \mathrm{P}$ \\
\hline 14 & $7.2,12.4,13.2,18.4$ & $7 \mathrm{~N}$ \\
\hline 15 & $11.3,21.1,17.3,18.1$ & $8 \mathrm{P}$ \\
\hline 16 & $8.4,9.2,14.4,15.2$ & $8 \mathrm{~N}$ \\
\hline 17 & $7.3,8.1,13.3,14.1$ & $9 \mathrm{P}$ \\
\hline 18 & $10.4,11.2,16.4,17.2$ & $9 \mathrm{~N}$ \\
\hline 19 & $1.5,4.5,7.5,10.5,13.5,16.5$ & $0 \mathrm{~A}$ \\
\hline
\end{tabular}




\begin{tabular}{|l|l|l|}
\hline 20 & $3.5,6.5,9.5,12.5,15.5,18.5$ & $0 \mathrm{~B}$ \\
\hline 21 & $2.3,5.5,8.5,11.5,14.5,17.5$ & $0 \mathrm{C}$ \\
\hline
\end{tabular}

\section{Advantages of Matrix Converters:}

The advantages of using the Matrix Converters are given as below:

[1] An inherent bi-directional power flow.

[2] A sinusoidal input-output waveforms with a moderate switching frequency

[3] It is compact due to the absence of DC-link reactive components.

[4] A controllable input power factor which is independent of the output load current.

\section{Limitations of Matrix Converters:}

The limitations of using the Matrix Converters are given as below:

[1] An intrinsic limitation of 0.866 as the output-input voltage ratio.

[2] The commutation and the protection of the switches

[3] The non-availability of the bilateral fully controlled monolithic switches which are capable of high frequency operation.

[4] A complex control law implementation

\section{Simulation Results:}

When a DMC which is represented in Figure 1 was simulated in the software which is known as MATLAB/Simulink, a number of worthwhile results were obtained as shown in Figure 6 and Figure 7. Some studies have been done by using the following parameters such as the source voltage equal to 415 Volts, $50 \mathrm{~Hz}$, the load resistance $\mathrm{R}=3 \mathrm{Ohms}$, Load inductance $\mathrm{L}=500 \mathrm{mH}$, Modulation Index $\mathrm{m}=0.5$, output frequency $\mathrm{f}_{0}=25 \mathrm{~Hz}$, switching frequency $\mathrm{f}_{\mathrm{s}}=1 / \mathrm{T}_{\mathrm{s}}=5 \mathrm{kHz}$. In addition, it can be observed that the DMC can generate the output frequencies that are not restricted by the source frequency.

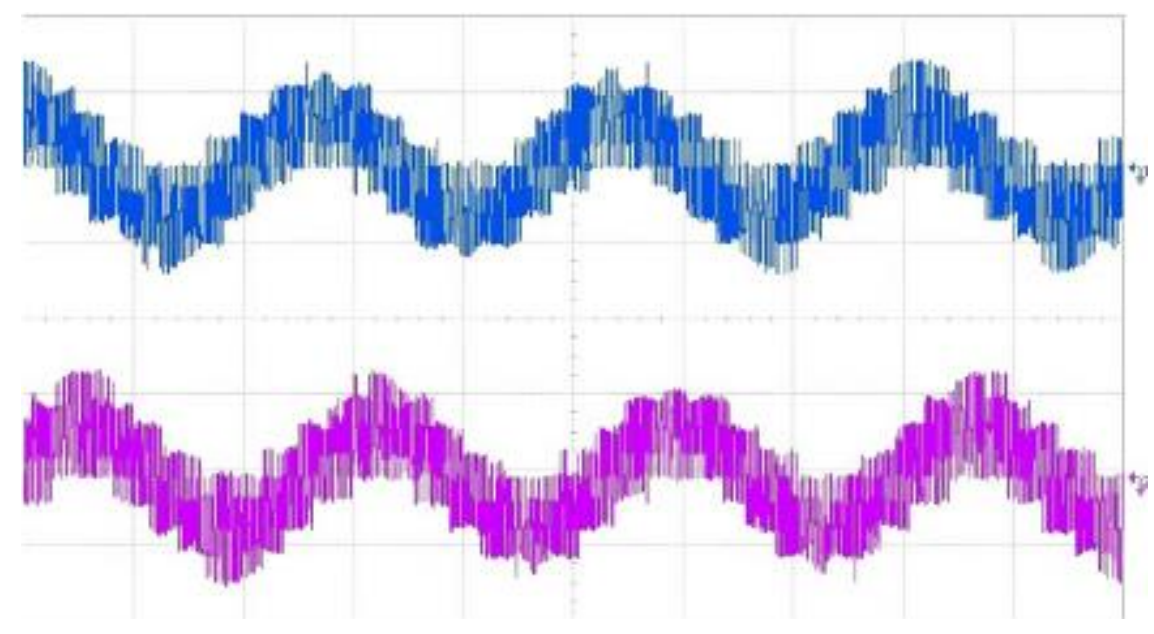

Figure 5 Three Phase Output Line Voltage Waveform of a DMC 


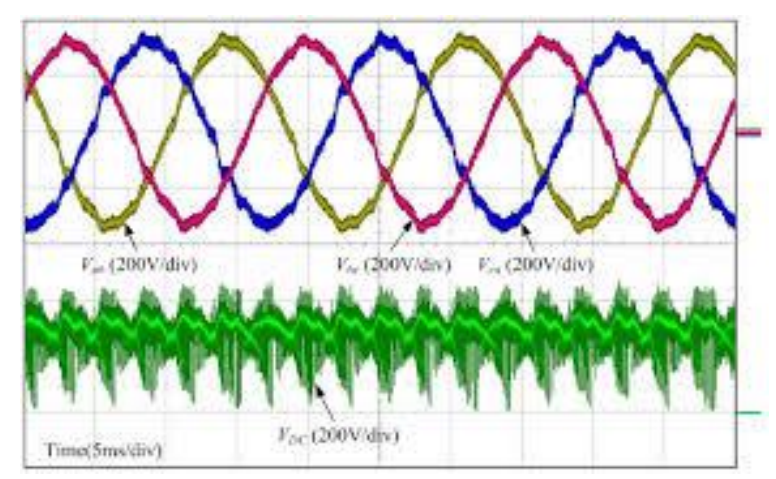

Figure 6 Output Phase Voltage Waveform of a DMC

\section{Conclusion:}

The working principle of the DMC controller with the SVPWM approach has been presented. All the necessary equations have been clearly explained and used during the process of simulation. It can be believed that this research paper presents useful information in order to understand and study the control of this exciting converter.

\section{References:}

[1] A. Alesina and M. G. B. Venturini, "Analysis and Design of Optimum Amplitude Nine-Switch Direct AC-AC Converters", IEEE Transactions on Power Electronics, Volume 4, No. 1, January 1989.

[2] P. Wheeler, J. Rodriguez, J. Clare, L. Empringham, A. Weinstein, "Matrix Converters: A Technology Review", IEEE Transactions on Industrial Electronics, Volume 49, No. 2, April 2002.

[3] H. Altum, S. Sunter, "Matrix Converter Induction Motor Drive: Modeling, Simulation and Control”, International Journal of Pattern Recognition and Artificial Intelligence (IJPRAI), Volume 5, Issue 6, May 2013.

[4] J. Rodriguez, E. Silva, R. Burgos, F. Blaabjerk, "Modeling, Analysis and Simulation of Matrix Converter", IEEE Transactions on Image Processing, Volume 43, No. 6, February 1998, pp. 346-357.

[5] Saul Lopez Arevalo, "Matrix Converter for Frequency Changing Power Supply Applications", International Journal of Electronics Engineering and Computer Science (IJEECS), Volume 8, Issue 4, July 2011.

[6] Bimal K. Bose, "Modern Power Electronics and AC Drives", Tata McGraw Hill Publications, Fourth Edition, April 2013.

[7] Muhammad H. Rashid, "Power Electronics: Circuits, Devices and Applications", Wiley Publication Group, Second Edition, May 2014. 